\title{
Teachers', Pupils' and Parents' Perceptions on the use of Chinyanja as a Medium of Instruction in Selected Lower Primary Schools in Lusaka District, Zambia
}

\author{
*Esau G Mbewe, Beatrice Matafwali, Sylvia Mwanza Kabaghe \\ University of Zambia \\ *Department of Educational Psychology, Sociology and Special Education \\ The University of Zambia, P.O Box 32379, Lusaka Zambia
}

\begin{abstract}
The study investigated perceptions of teachers, pupils and parents towards using Chinyanja as a medium of instruction in Lusaka district. A case study design was used to collect data. The study sample comprised 30 teachers, 30 parents and 63 parents. The study established that teachers perceived Chinyanja as beneficial to the pupils in the early stages of literacy development because it enhanced increased teacher-pupil interaction in the learning process. This study also established that pupils do not support learning in Chinyanja because they are not proud of it and they are not proficient in Chinyanja used in class. With parents, they regarded using Chinyanja as a medium of instruction as retrogressive and not beneficial to their children in acquiring future success in different life endeavours.
\end{abstract}

Keywords: medium of instruction, teachers, pupils, perception, Chinyanja, language, lower and primary schools.

\section{BACKGROUND OF THE STUDY}

\subsection{Introduction}

This study investigated teacher, parents and pupil perception on the use of Chinyanja as the medium of instruction in lower primary schools. In order to understand the introduction of this new policy of using chinyanja in first grade, it is important to outline the history of educational policies regarding policies in Zambia. The evolution in medium of instruction in education dates as far back as the period before the coming of the missionaries in Northern Rhodesia. During the missionary period, local languages were taught as a subject and used as a medium of instruction from sub-standard A to standard four because it was believed that a local language was a powerful linguistic instrument that one could use to impart knowledge in the local community (Manchishi 2004). A local language which was chosen in an area was used as a medium of instruction for example Silozi was used in western province. English only became the medium of instruction from standard five and whilst a local language was taught as a subject. In 1963 UNESCO commissioned a study of reviewing the Zambian education system and to find ways of improving it. UNESCO recommended that English should be introduced as a medium of instruction in quest to improve the education system. Hence, when Northern Rhodesia became independent in 1964, the government chose to implement the UNESCO recommendations and English was introduced as a medium of instruction from grade one to tertiary level. This was done because it was believed that English would promote national unity and that the earlier a language was started the better it was for the learners (Mwanakatwe, 1968). The change in the medium of instruction from local languages to English was done through the 1966 Education Act, the statutory instrument number $3122^{\text {nd }}$ November 1966 Education Act ( Manchishi 2004; Mwanakatwe, 1968; Mwanakatwe, 1973; Ministry of Education, 1996; Ministry of Education, 1992 ).

Although there was the above change in the medium of instruction there were reports from conducted studies that children do not easily acquire basic literacy skills when they are taught using the language that is not familiar to them because children have to learn two complex skills simultaneously. Studies in literate societies have made plausible discoveries that a rather high level of proficiency in the language of instruction is required for children to benefit from reading instruction in school 
(Dickinson, McCabe, Anastasopoulos, Peisner-Feinberg, \& Poe, 2003). Therefore, the Zambian education policy then meant that leaners were to be taught using the language that was relatively unfamiliar this approach compromised the quality of education being offered not only at primary school level, but also at higher levels (Kelly, 2000).

English medium of instruction policy, however, did not achieve desired results. The learners who had succeeded in generating the competences in reading were very few. A study by Southern African Consortium for Monitoring Educational Quality (SACMEQ, 1998) on reading performance levels of grade six pupils in the Zambian Basic schools revealed that in 1995, out of the 148 grade six pupils in the target population, only $25 \%$ were able to read at defined maximum levels and only $3 \%$ were able to read at desired levels (Nkamba, and Kanyika, 1998). Therefore, the 30 year period between 1965 and 1995 saw a number of attempts to reverse this 'straight-for-English' approach. For instance, in 1977, the new policy, 'Educational Reform: Proposals and Recommendations'(Ministry of Education), provided that teachers be allowed to explain concepts that might otherwise not be understood through the medium of English, in one of the seven official local languages, provided a majority of pupils in a class could understand this vernacular language ( Ministry of Education, 1977).

In 1996, there was a change in education policy whereby 'focus on learning' was replaced by a more liberal policy 'Educating our future'. The Ministry of Education stipulates the following:

a) A fundamental aim of the curriculum for lower and middle basic classes is to enable pupils to read and write, correctly and confidently, in a Zambian language and in English, and to acquire basic Numeracy and problem-solving skills.

b) All pupils will be given an opportunity to learn the initial skills of reading and writing in a local language. Whereas English will remain as the official medium of instruction (Ministry of Education, 1996: 30).

This marked the introduction of the Primary Reading Program. In 1998, New Break Through to Literacy, an initiative of a South African non-governmental organization, Molteno project was piloted in Kasama and Mungwi in Northern Zambia. This was among grade one learners. IciBemba was used as the language of initial literacy. The results of the project were positive as learners were able to read in grade one and by the time they reached grade two they were able to read at a level equivalent to those in grade four (Ministry of Education, 2001). The Molten project was later renamed New Break Through to Literacy. In 2000, the project was extended to Mongu where Lozi was used as a language of initial literacy and Chipata and Lusaka where Chinyanja was used to teach initial literacy. In 2003, the New Break Through to Literacy course was extended to all the provinces of Zambia (Ministry of Education (2003a).

Kotze and Higgins, (1999) noted that the evaluation report on pilot programme carried out in Kasama Northern province of Zambia during 1998 states that 'the programme was an unqualified success; children in NBTL classes were reading and writing at a level equivalent to Grade 4 or higher in nonNBTL classes'. Despite these achievements, there were reported instances where children failed to make improvement at reading despite this effective literacy program in place. The Ministry of Education Report on National assessment (2003) concluded that the proportion of pupils attaining the expected minimum grade level of competence in reading in 2003 was at $1.7 \%$ for Lusaka province and $0.7 \%$ for Eastern province (Ministry of Education , 2003), which indicates that the expectations for children's performance were still low. A follow-up study was conducted in the same year to verify the earlier findings for Lusaka and Eastern provinces respectively. Results of the follow-up showed improved levels of $24 \%$ for Lusaka province and $9.4 \%$ for Eastern province. It was, however, observed that although the results of the verification study were somewhat higher than the prior results, they fell short of expectations (Ministry of Education; 2003).

Matafwali (2010) observed that even if the use of familiar language as the initial language of instruction was introduced in 2000, the reading levels of the majority of Zambian children were regrettably still low by 2005. Specifically, her study sought to know how lack of proficiency in the language of instruction explains difficulties in becoming a conventional reader in a Zambian language and English. The study further sought to evaluate the progress made by children in grade one and Two. The study revealed that lack of proficiency in the initial language of instruction was the hallmark for poor reading and writing skills observed in majority of Zambian children. When deficits in oral language converge with deficits in cognitive skills, children are at substantial risk of 
developing reading difficulties (Matafwali, 2010). From the above cited studies, one may argue that the Primary Reading Programe was not successful in addressing low literacy levels as low literacy levels still persist among the Zambian children among the Primary school graders.

The above failure of the curriculum to address low literacy levels motivated the Ministry of Education, Science, Vocational Training and Early Education to change the medium of instruction from English to using the familiar language in 2013. Regarding the change in medium of instruction the following has been indicated; "Language of instruction from Grade 1-4 in all the learning areas will be in a familiar language, while English will be an official language of instruction from grade 5 upwards ( Curriculum Development Center 2013: 30)". It was further pointed out that the core areas that pupils will be learning from grade one to grade four are literacy and languages, or sign language ; Integrated Science; Social Studies; Mathematics; Creative and Technology Studies (CTS) (Curriculum Development Center, 2013). The above change in medium of instruction from grade one to grade four entails that familiar languages will be used to teach all the above core learning areas except English subject unlike in the past where familiar languages were only used to teach initial literacy skills and Zambian Languages. The above change in medium of instruction brings forth a number of questions. Following a study by Mwanza ( 2012) that has shown that in Lusaka district the dominant language of play in medium and high density areas is Chinyanja and that the dominant language of play in Low density areas is English, one may want to know the perceptions of teachers and pupils are towards the use of a familiar language for instance to learn literacy and languages, or sign language; Integrated Science; Social Studies; Mathematics; Creative and Technology Studies (CTS) in the learning process in these areas. One may further want to know the perceptions of parents towards the Chinyanja as a medium of instruction in Lusaka district. These questions could not be adequately answered without empirical evidence or conducting a study. Hence there was a need for this study.

\subsection{Statement of the Problem}

Research has suggested that learners acquire basic literacy skills when the language which is familiar to them is used as a language of instruction and that Lusaka district is a cosmopolitan environment characterized by language diversity (Matafwali, 2010; Banda, Mostert, Gerd \& Wikan 2012; Mwanza, 2012; Kumwenda 2010, Mwanza-Kabaghe 2015). Despite Lusaka district being a cosmopolitan environment characterized by language diversity, the curriculum has designated Chinyanja as a medium of instruction from grade 1-4 in Lusaka Province (Curriculum development Centre, 2013). We do not know the perceptions that teachers; pupils and parents have about the use of Chinyanja as a medium of instruction in Lusaka district, hence there was need for this study.

\subsection{Aim}

The purpose of the study was to establish perceptions that teachers, pupils and parents have towards the use of Chinyanja as a medium of instruction in lower Primary schools in Lusaka district. The study also sought to determine the challenges that teachers and pupils are facing towards the implementation of Chinyanja as a medium of instruction in lower Primary schools in Lusaka district.

\subsection{Study Objectives}

The study was guided by the following objective

(1) To establish perceptions of teachers towards the use of Chinyanja as a medium of instruction in Lusaka district

(2) To determine perceptions that pupils have about the use of Chinyanja as a medium of instruction in Lusaka district

(3) To establish the perception of parents towards the use of Chinyanja as a medium of instruction in Lusaka district

(4) To determine challenges that teachers and pupils are facing in implementing the use of Chinyanja as a medium of instruction in lower Primary schools in Lusaka district

\subsection{Research Questions}

The study was guided by the following questions; 
(1) What are the perceptions of teachers towards the use of Chinyanja as a medium of instruction in Lusaka district?

(2) What are the perceptions of pupils towards the use of Chinyanja as a medium of instruction in Lusaka district?

(3) What are the perceptions of parents towards the use of Chinyanja as a medium of instruction in Lusaka district?

(4) What are the challenges that teachers and pupils face when implementing the use of Chinyanja as a medium of instruction in Lusaka district?

\subsection{Theoretical Underpining}

This study was guided by Levy Vygotsky social constructivism theory of cognitive development. The theory stresses the importance of culture, language and more knowledgeable others in cognitive development. Language provides a means for expressing ideas and asking questions, the categories and concepts for thinking. Vygotsky suggests that learners or children use languages in form of private speech to organize their thoughts when accomplishing cognitive activities such as directing attention towards a given task, solving problems, planning, forming concepts and gaining self-control (Woolfolk,1995; Vygotsky,1978). Therefore, using familiar language and cultural appropriate examples in the course of learning would enable significant others to scaffold pupils in the learning process in order to move to another level of development. There is also overwhelming evidence that cognitive development is culture specific. Therefore, a child's cultural language has influence on children's cognitive development. For example, the way people think about relations between objects in space. Children who learn a language that has no words for spatial concepts such as in, on, in front of, behind, to the left, and to the left and to the right will acquire cognitive categories that are different from those of people in North America. These children or individuals have difficulties distinguishing between the left and the right sides of objects and they tend not to use the symbolic association with left and right hands that North Americans do (Nissbett 2004). This suggests that education must be done using a language that is familiar to the child if the education is to be meaningful to the child.

\section{METHOdOLOGY OF THE STUdY}

\subsection{Research Design}

The researcher adopted a case study design. According to Polit and Hungler (1983) cited in Mwanza (2012), Case studies are detailed investigations of individuals, groups, institutions or other social units. A case study has one person, entity, a study of one thing; it is identified as one of the many. A case study may be of one person, class, district, country, continent or a family. A case study design was used because it allows the researcher to have an in-depth and detailed understanding of a single unit, such as one individual, one group, one organization, or one program. A case study provides a unique example of real people in real situations, enabling readers to understand ideas more clearly than simply by presenting them with abstract theories or principles. It further enables readers to understand how ideas and abstract principles can fit together.

\subsection{Data Collection and Sampling Procedure}

The researcher triangulated the data collection instruments in order to ensure validity and credibility of the research findings. According to Anderson and Asenault (1998), triangulation helps to eliminate bias and can help to detect errors. Therefore, the researcher used non-participant observation, semistructured interview guides and focused group discussion when collecting the data. Semi-structured interview guides were developed for use with teachers and parents to gain an insight into the reasons behind their perception of Chinyanja as a medium of instruction in Lusaka district. Simple random was used when selecting 30 parents and 63 pupils to give them all an equal chance of participating in the study whilst purposive sampling was used to select teachers teaching in lower primary schools because they had the information relevant for the study.

\subsection{Focus Group Discussions}

Focus Group Discussions (FGDs) are forms of interviews in which more than one person is involved (Bryman, 2008). Wellington (2000) recommends a small group of six to ten participants per session. The researcher used focus group discussion because they were helpful in getting the holistic view of the pupils towards using as a medium of instruction in Lusaka district. The researcher also used Focused discussion because the pupils had the similar characteristics. 


\subsection{Observation Schedule}

The researcher employed an observation schedule at each of the three selected schools in order to yield detailed first-hand descriptions of classroom activities, interactions and processes that influenced teacher-pupil perception towards Chinyanja as a medium of instruction in lower primary schools in Lusaka district,

\subsection{Interview Guides}

These were: semi-structured interview guides. Semi-structured interview guides were developed for use with teachers and parents to gain an insight into the reasons behind their perception of Chinyanja as a medium of instruction in Lusaka district. Sidhu (2006), documents that an interview is a two way method which allows an exchange of ideas and information. In an interview, the researcher collects data from respondents in face- to- face contact. The aim of the interview is to help in the construction and understanding of reality. The interview guides were also used because they are flexible and allows the researcher to ask a respondent a follow up question if need arises. Interviews were further used because the respondent may felt to be part of the team and freely participated in the study.

\subsection{Data Analysis}

A mixed methods approach which involved a concurrent triangulation of both methodological and data sources was used during data analysis. Therefore, both quantitative and qualitative data analysis techniques were employed. The data obtained through interviews, focus group discussion and observations were analysed thematically using content analysis, as themes and sub-themes emerged. Quantitative data from questionnaires were first entered into the computer and later analysed statistically using the Scientific Package for Social Sciences (SPSS) software version 16.0. This was for purposes of generating simple descriptive statistics in form of frequencies, tables and graphs. While the two data types were analysed separately, there was need to triangulate them for easy interpretation. This was done by looking for key themes in both the qualitative and quantitative data, which could be fitted together into single categories.

\section{FINDINGS AND DISCUSSION}

It is worth noting that the perception of teachers towards using Chinyanja as a medium of instruction in lower Primary school in Lusaka district was observed to be positive. The study established that Chinyanja was perceived as beneficial to the pupils in the early stages of literacy development and that pupils participate more in the process of learning when Chinyanja is used as a medium of instruction than when English is used. It was further established that most of the learners in government schools use Chinyanja so they respond well and express themselves freely without feeling shy in the process of learning when Chinyanja is used as a medium of instruction. Teachers further noted that pupils understand and learn to read and write fast just in grade one and they can take down dictation if Chinyanja their language of play is used to teach them. This can be seen in the chart below on figure 1 .

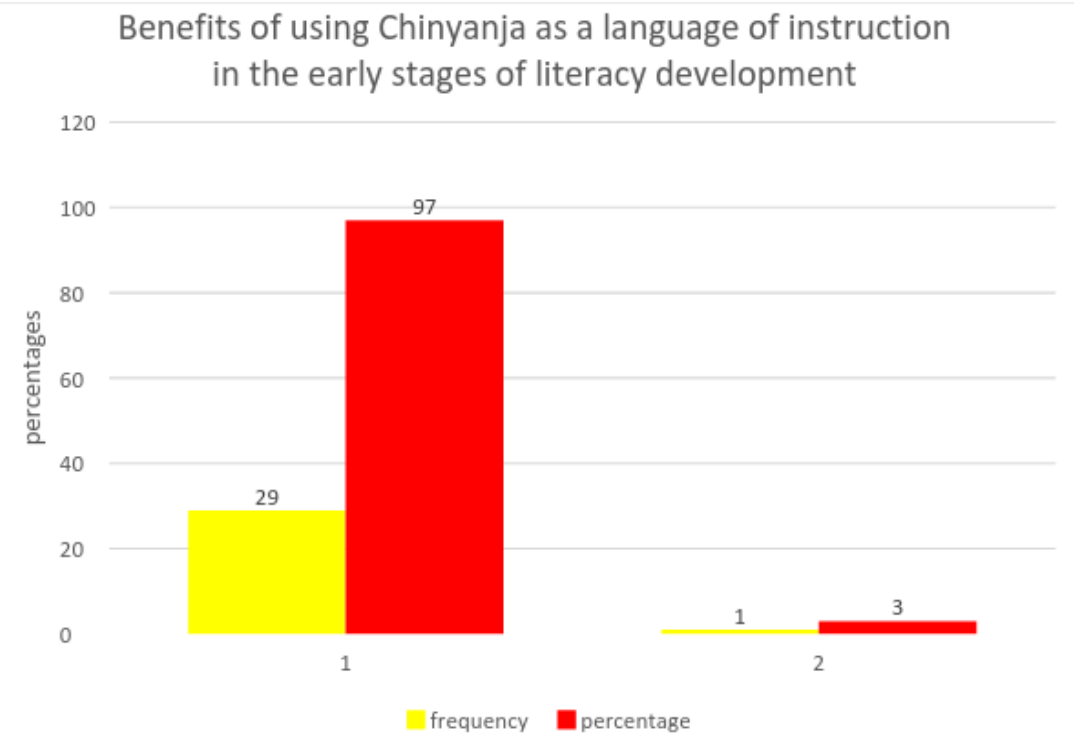

Figure1. Teachers' views of using Chinyanja as a medium of instruction 
The above findings suggest that teachers hold the belief that using Chinyanja as a language of instruction would positively influence the posit results of a learning process more especially on the part of the learners as pointed out by Matafwali (2010) and Vygotsky (1978) social cultural theory of conginitive development. Khejeri (2014) found that very few teachers wanted their learners to use Mother Tongue during instruction and that Mother Tongue holds very little value in comparison to English. Unlike Khejeri (2014), this study has established that teaches are fully in support of using Chinyanja as a language of instruction at lower primary school in Lusaka district. Adekola (2008) also found that majority of the teachers had a positive perception towards literacy through mother tongue in Nigerian junior schools.

This study also established that pupils have a negative perception towards using Chinyanja as a medium of instruction in lower primary school in Lusaka district. Data collected using focused group discussion showed that pupils preferred using English to Chinyanja as a medium of instruction. The data collected through interviews from grade one and two also showed that pupils preferred using English as a medium of instruction to Chinyanja. The pupils did not prefer to use Chinyanja as a medium of instruction because they viewed it to be less beneficial compared to English. Other pupils noted that Chinyanja was difficult to speak and they did not understand it because in homes and some private schools where these pupils were coming from, speaking Chinyanja was not encouraged by their caregivers. Some children also preferred using English to Chinyanja because they perceive communicating in English as a sign of being an intelligent pupil and a good boy Igirl in the eyes of their caregivers. This can be seen in the chart below on figure 2;

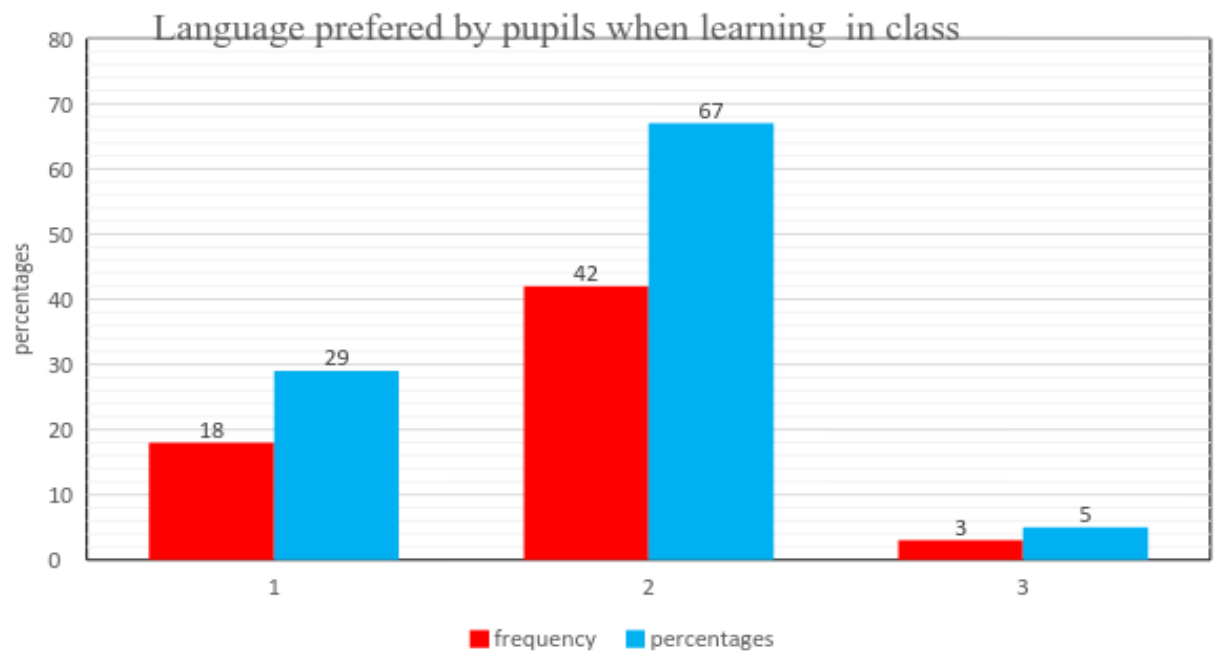

Figure2. Pupils' medium of instruction preference

The above results indicate that majority of pupils do not believe in using Chinyanja as a language of instruction from grade one to grade four in Lusaka district because they do not associate it to success. It appears that's there is little faith in Chinanja by pupiuls because they do not get enough motivation from their parents to use it as less value is placed on it. This is against the research findings that pointed out learning in a familiar language influences academic achievement ( Kumwenda 2010). Bachore (2014) confirms the above results where it was established that almost half of the sample students had negative attitude and perception towards using mother tongue as a medium of instruction. Ndamba (2008) also found that learners have a negative perception towards using familiar language as a language of instruction.

With regard to parents, the study revealed that they hold the belief that learning using English as a medium of instruction would increase the future prospects of their children being successful. Parents noted that when children grow up and progress to higher education, English would be used as a medium of learning so it is better for their children to be taught using English so that they can have a strong foundation in it which they viewed as a language which improves a pupils prospects of getting a job in the future. Parents further believe that learning in English creates confidence in their children and promote interactions of children with their peers from different ethnic background. MwanzaKabaghe (2015) and Mbewe (2015) acknowledges that parents view English as a language of power which is associated with success as opposed to using Chinyanja which is often viewed in low esteem. 
Parents pointed out that when children start learning using English as a language of instruction, it creates a strong background for the teachers and strengthen on the knowledge of the pupils in English such that they know more on how best to communicate in English in later grades of upper and secondary level. Parents views are summarized on the figure 3 below;

Language prefered by parents to be used to teach their children from grade one to grade four

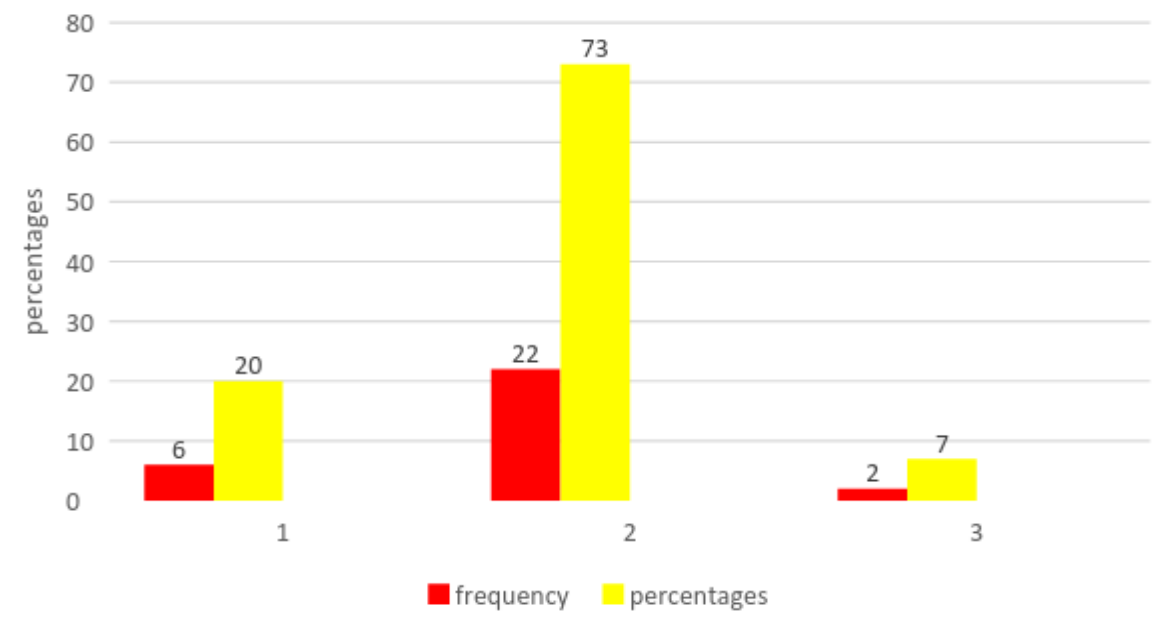

Figure3. Parents' language preferences

From the above findings, it appears that learning in English creates confidence in children and promote interactions of children with their peers from different ethnic background. It appears that parents view English as a language of power which is associated with success as opposed to using Chinyanja which is often viewed in low esteem. Awedoba (2001) found that at the initial interview encounter nearly all the parents interviewed preferred as Medium of instruction the use of English rather than the local language, Kasem. Their reasons were that as a mother tongue and prevalent language of the community, children are sufficiently equipped in Kasem and its learning need not therefore be considered as a priority; parents further held the view that good command of Kasem did not necessarily enhance future prospects. Although Matafwali (2010) and Vygotsky (1978) suggest that children easily acquire basic literacy skills and organize their thoughts when a familiar language is used as a medium of instruction, parents in Lusaka district down play the importance of using Chinyanja as a language of instruction. The above view shows that parents do not appreciate the importance of education in a familiar language. Parents associate success and intelligence to learning using English as a medium of instruction. Regarding such negative views to using Chinyanja as a language of instruction, Lawal (2005) cited in Olaolorun, Ikonta and Adeosun, (2013) documents that parents out of ignorance insulate the children from the mother tongue to induce facility in the use of English Language thus depriving children of a basic source of education and imaginative development.

The study also identified the challenges that teachers and pupils were facing in implementation of Chinyanja as a medium of instruction in lower primary school in Lusaka district. The identified challenges included; classes are overcrowded, teachers finding challenges to explain to pupils in Chinyanja some words like volume and matter' in Integrated Science. The teachers noted that some books like those for creative and technological studies are still written in English. It was also found that teachers were not trained to teach in local languages, for example out of the 30 teachers who participated in this study only 10 indicated that they were trained, the other 20 said that they were not trained. The 10 teachers who were found to be trained, also indicated that they were not adequately trained in various institutions where they received their tertiary education because the training which they received about teaching local language was conducted using English and the materials they used were also written in English. Therefore, it is difficult for teachers who are also not familiar with Chinyanja to translate books which are still written in English when using Chinyanja in the process of learning. It was further revealed that although effort is being made to use Chinyanja as a medium of instruction, most of the tests or exercises that pupils are given are prepared in English because most of the books are still written in English. It is also difficult for the pupils to understand 
fully what they are taught because there are no books for pupils to be given out in the process of learning for them to look at what the teacher is teaching them. The other respondents also noted the following challenges, most of the learners were coming from private schools so even the learners had problems with Chinyanja, there are too many pupils in classes; not all pupils are well acquainted with the language of instruction, and some words and formulas are not easy to translate in Chinyanja. The above views further suggest that lack lack of familiarity with the language of instruction, inadequate teaching and learning materials, over enrollment and lack of pedagogical knowledge were among challenges being faced by teachers and pupils in the implementation of Chinyanja as a language of instruction in Lusaka district. Ojanen (2007) also document that for teachers to give adequate instruction in Zambian native languages, they needed to have profound knowledge of the language, its linguistics, pronunciation and standardised spelling. She pointed out that it was difficult for teachers to have knowledge of the language, its linguistics, pronunciation and standardized spelling because they were schooled in the English era; hence, the system that was followed in Zambia of using the children's familiar language was facing the mother tongue problem in a country of dozens of languages. Gacheche (2010) contend that problem posed by the linguistic heterogeneity that mothertongue medium policy could only be applied successfully in most rural areas that are linguistically homogeneous. The complex and cosmopolitan nature of urban areas is likely militating against this policy. Gacheche (ibid) also found that that lack of instructional materials also hinders teacher's transmission of content in local languages to learners. Teachers did not have the necessary instructional materials to offer meaningful education to pupils in the local language used as a medium of instruction. This may affect the learning outcome.

The study further determined the following measures that could be taken to overcome the challenges that teachers and pupils were facing in implementation of Chinyanja as a medium of instruction in Lusaka district: Various or respective schools should come up with programs like workshops to orient teachers on effective teaching of Chinyanja and the government through the ministry of education and curriculum development Centre should provide adequate teaching and learning resources for the new medium of instruction and the syllabus ; teachers workshops should last for more than three days as opposed to compacting all what may be learnt in six months into three days because this does not help teachers to understand what they are supposed to understand; teachers when they go to collages they should be taught how to teach local languages using local languages and writing dictionaries that translate English words in Chinyanja; instructions should be given in Chinyanja in everyday life for example road signs, pupils notices and letters to the parents because this would encourage the use of local languages not only in schools but also in the communities; cross-coding so that the difficult words in Chinyanja can be explained in English and so that the learners who does not understand Chinyanja are helped also to benefit from the learning process; buying books for the pupils so that they can easily look at the pictures of what the teacher is talking about in the process of teaching; making use of Chinyanja in everyday communication purposes and creating ongoing lessons in schools for teachers on how Chinyanja can be taught in schools; distributing more teaching and learning materials like books in Chinyanja in schools and reduce the enrollment from 75-90 to 45-50 pupils in class; re-translating Chinyanja books into Chinyanja that is spoken in Lusaka from Chinyanja that is spoken in rural areas for example, changing words like 'mphika' in Chichewa to 'poto', meaning a pot in English, 'madzi' to 'manzi' which is commonly used in Lusaka in every day communication; the community should be actively involved in the implantation of Chinyanja as a medium of instruction in Lusaka district; tests in subjects like Creative and Technological Studies and text books should be prepared in local language upto grade five; continuation of producing books in Chinyanja; giving lower grades to teachers who knows Chinyanja well; employing specific teachers for Chinyanja who are fluent in it; the government especially the ministry of education should consider printing and delivering teaching materials is schools. Young (2009) cited in Gacheche (2010) noted that good practices in multilingual schools in Southeast Asia, in the Philippines, Vietnam, Thailand and Brunei, local community members made excellent teachers if trained before they taught, had regular in-service training and were involved in the production of instructional materials. The communities in these countries worked with linguists and ethnographers to develop first language materials with age-appropriate language and reflecting cultural situations familiar to learners. 


\section{CONCLUSION AND RECOMMENDATIONS}

\subsection{Conclusion}

In conclusion, the study has established that teachers have a positive perception of using Chinyanja as a language of instruction in Lusaka district because it increased pupil-teacher interaction in the learning process. The study has revealed that the parents seem to have a stronger belief in English than in Chinyanja because of the high social and economic status that parents attach to English thereby making them underscore the importance that comes along when a familiar language like Chinyanja is used as a language of instruction in lower Primary schools in Lusaka district. This study also established that pupils do not support learning in Chinyanja because they are not proud of it and they are not proficient in Chinyanja used in class. With parents, they regarded using Chinyanja as a medium of instruction as retrogressive and not beneficial to their children in acquiring future success in different life endeavours. The study also identified that translational and mispronunciations challenges; lack of pedagogical knowledge by teachers to teach in Chinyanja; language diversity; inadequate teaching and learning material; and lack of parental support for Chinyanja as language of instruction were among the challenges being faced by teachers and pupils in implementing Chinyanja as a medium of instruction. Measures that could be taken to overcome the challenges being faced included: training teachers in local languages; providing adequate teaching and learning resources; teachers and parents to promote the usage of Chinyanja outside class, teachers to come up with continuous profession development in schools and giving lower grades to teachers who knows Chinyanja well.

\subsection{Recommendations}

The parents must ensure that they promote the use of Chinyanja as a language of communication in their family holds so that children are exposed to Chinyanja early; teachers should make an effort as much as possible to communicate in Chinyanja to the pupils outside class and in important school gatherings in order to promote the usage of Chinyanja as a language of communication in Lusaka district; the government of Zambia through the Ministry of Education, Science, Vocational Training and Early Education should ensure Continuous Professional Development (CPD) for teachers in schools in order for them to be well vested with the new Curriculum Development Centre; the government of Zambia through the responsible ministry should ensure identifying teachers who are competent speakers of Chinyanja at the time of deployment; the government of Zambia should ensure that the training of teachers in collages in teaching local languages is done using local languages as a medium of instruction; the government through the responsible ministry should intensify sensitization and orientation of parents towards the benefits of using the familiar language as a medium of instruction in the learning process in order to change their negative perception; the Government through the responsible ministry should consider involving the parents in implementation of familiar language as a language of instruction, for example, making sure that there is an active involvement of the community in choosing the language which is familiar to them; the government of Zambia through the responsible ministry of education should consider investing in the production of more teaching and learning materials in Chinyanja that would easy the use of familiar language as a medium of instruction.

\section{REFERENCES}

Adekola, B. (2008).Perception of Junior Secondary School Teachers towards Literacy through Mother Tongue Education in Ogun State: International Journal of Emotional Psychology and Sport Ethics Vol. 10 2008: pp. 199-207

Anderson, G.E. and Arsenault, N. (1998). Fundamentals of Education Research. London: Falmer Press.

Awedoba( 2001). Examining the Cases: Attitudes Towards an Instruction in the Local Language. IEQ: American Institutes for Research.

Bachore M.M. (2014).Mother Tongue Based (MTB) Classroom Instruction: The Attitudes and Perceptions of School Community in Sidama Zone, Ethiopia: Research on Humanities and Social Sciences, Hawassa University.

Bryman, A. (2008). Social Research Methods. Oxford: Oxford University Press. 
Curriculum Development Centre (2013). Zambia Curriculum development framework. Lusaka: Curriculum development center.

Curriculum Development Centre (2000). The Basic School Curriculum Development Center. Lusaka: Ministry of Education.

Dickinson, D. K., \& Tabors, P. O. (Eds.). (2001). Beginning language with literacy: Young children learning at home and school. Baltimore: Brookes Publishing

Gacheche, K. (2010). Challenges in implementing a mother tongue-based language in-education policy: Policy and practice in Kenya: POLIS Journal Vol.4, Winter 2010

Hassanzadeh, N., Shayegh,K., Hoseini, F. (2011). The Impact of Education and Awareness in Mother Tongue Grammar on Learning Foreign Languages: Journal of Academic and Applied Studies Vol. 1(3) September 2011, pp. 39-5

Kelly, M.J. (2000). Reading Comes First: Primary Reading Program Baseline Reading Study: Lusaka: image publishers

Khejeri, M (2014). Teachers' Attitudes towards the Use of Mother Tongue as a Language of Instruction in Lower Primary Schools in Hamisi District, Kenya: International Journal of Humanities and Social Science Vol. 4 No. 1; January 2014.

Kumwenda,.B.C (2010). Initial Reading Performance in Chinyanja InMult-Ethnic Classes: A Case of selected schools in Chipata Urban: M.A Dissertation. Unpublished: University of Zambia.

Ojanen, E. (2007). Sewero La-ma-u - A phonetic approach to literacy teaching in Zambia. Unpublished Master of Social Science (Psychology) Dissertation. Jyväskylä: University of Jyväskylä.

Olaolorun, M.O, Ikonta N. R. and Adeosun, A. O.; (2013) Parental Attitude to the Learning of L1 in Nigerian Secondary Schools. British Journal of Arts and Social Sciences Vol.13 No.I

Manchishi, P.C. (2004). The Status of Indigenous languages in Institutions of Learning in Zambia: 'Past, Present and Future'. In. The African Symposium Vol. 4 No. 1.per, R. (1989) Language planning and social change. Cam

Matafwali, B (2010). The Role of Oral Language in the Acquisition of Early Literacy Skills: A Case of Zambian Languages and English. A Doctor of Philosophy Thesis: Unpublished. University of Zambia.

Mbewe E. G (2015) An Investigation of Teachers', Pupils' and Parents' Perceptions towards the Use of Chinyanja as a Medium of Instruction: A Case of Selected Lower Primary Schools in Lusaka District. M.A Dissertation. Unpublished: University of Zambia.

Ministry of Education (1992).Focus on Learning. Lusaka: Ministry of Education

Ministry of Education (1996). Educating Our Future. National Education Policy on Education. Lusaka: Ministry of Education

Ministry of Education (1977). Educational Reforms. Lusaka: Ministry of Education

Ministry of Education. (2001). New Break through to Literacy. Lusaka: Ministry of Education

Ministry of Education (2002) Follow up to the 1999 Baseline study. Primary Reading Program. Lusaka: Longman

Ministry of Education. (2003). Learning Achievement at the Middle Basic Level: Zambia National Assessment Survey Report (2003). Lusaka: Examinations Council of Zambia.

Ministry of Education. (2003a, 3rd edition). Zambian New Breakthrough to Literacy. Primary Reading Programme. Teacher's Book. Grade One. Lusaka: Longman

Mwanakatwe, J.M.(1968) The Growth Of Education In Zambia. Lusaka: Oxford University Press.

Mwanakatwe, J. M. (1973). Language and National Unity. Bulletin of the Zambia Language Group, Vol. 1 No. 2 pp $2-18$.

Mwanza D. S (2012). The Language of Initial Literacy in a Cosmopolitan Environment: A Case of Cinyanja in Lusaka District. M.A Dissertation. Unpublished: University of Zambia.

Mwanza-Kabaghe . S ( 2015) Preschool, Executive functions and Oral Language as Predictors of Literacy and Numeracy skills in First Grade. Phd Thesis: Unpublished. University of Zambia.

Ndamba, G.T.(2008). Mother Tongue Usage in Learning: An Examination of Language Preferences in Zimbabwe: The Journal of Pan African Studies, vol.2, no.4, June 2008. 
Teachers', Pupils' and Parents' Perceptions on the use of Chinyanja as a Medium of Instruction in Selected Lower Primary Schools in Lusaka District, Zambia

Nisbett, Richard E. (2004). The Geography of Thought: How Asians and Westerners Think Differently and Why. New York: Free Press

Nkamba, M. and Kanyaka, J (1998). The quality of Education: Some policy suggestions Based on a Survey of Schools in Zambia. SACMEQ Policy Research: Report No 5, Paris \& Lusaka. Ministry Education.

Sidhu, K.S. (2006). Methodology of Research in Education. New Delhi: Sterling Publishers Private Limited.

Vygotsky, L. (1978). Mind in society. Cambridge, MA: Harvard University Press.

Wellington, J. (2000). Educational Research: Contemporary Issues and Practical Approaches. London: Continuum.

Woolfolk A.E (1995). Educational psychology. Boston: Houston Mifflin Young, C. (2009) Good practices in mother tongue-first multilingual education. In: M. Redmond, ed. Mother Tongue as Bridge Language of Instruction: Policies and Experiences in Southeast Asia. Bangkok: The Southeast Asian Ministers of Education Organization (SEAMEO) Secretariat, pp. 120-135.

\section{AUTHORS' BIOGRAPHY}

Esau G mbewe, is a Part-time lecturer in the Department of Educational Psychology, Sociology, and special Education at the University of Zambia. He holds a masters degree in Educational psychology from the University of Zambia. Esau also holds a degree in special Education from the University of Zambia. He has three years of teaching and tutoring experiencing at the University of Zambia and more than five years of teaching at Secondary School level in social sciences department. He also holds profound experience in early childhood research and data collection and he is so passionate about issues surrounding literacy and learning.

Beatrice Matafwali, is a Senior lecturer in the Department of Educational Psychology, Sociology, and special Education at the University of Zambia. She holds a doctoral degree in special Education from the University of Zambia/Leiden University in the Netherlands. Beatrice also holds a masters degree in Education, Bachelor of arts degree with education, and Bachelor of laws degree and several other professional qualification from various disciplines. She has been teaching special Education for more than ten years now and she has conducted extensive research in Literacy, Early childhood studies and child assessment, and disability studies.

Sylvia Mwanza Kabaghe, is a lecturer in the Department of Educational Psychology, Sociology, and special Education at the University of Zambia. She holds a doctoral degree in Educational psychology from the University of Zambia /Leiden University in the Netherlands. Sylvia also holds a masters degree in Educational psychology, Bachelor of Education degree (Special education). She has been teaching at the University of Zambia for more than five years now and Some of her areas she has dwelt much in research include but not limited to developmental psychology and literacy. 